\title{
The Catalytic Function of Renalase: A Decade of Phantoms.
}

\author{
Graham R. Moran
}

Department of Chemistry and Biochemistry, University of Wisconsin-Milwaukee, 3210 N. Cramer St, Milwaukee, Wisconsin 53211-3209.

Correspondence should be addressed:

Ph: (414) 2295031

Fax: (414) 2295530

Email: moran@uwm.edu 


\section{Abstract}

Ten years after the initial identification of human renalase the first genuinely catalytic substrates have been identified. Throughout the prior decade a consensus belief that renalase is produced predominantly by the kidney and catalytically oxidizes catecholamines in order to lower blood pressure and slow the heart has prevailed. This belief was, however, based on fundamentally flawed scientific observations that did not include control reactions to account for the well-known autoxidation of catecholamines in oxygenated solutions. Nonetheless, the initial claims have served as the kernel for a rapidly expanding body of research largely predicated on the belief that catecholamines are substrates for this enzyme. The proliferation of scientific studies pertaining to renalase as a hormone has proceeded unabated despite wellreasoned expressions of dissent that have indicated the deficiencies of the initial observations and other inconsistencies.

Our group has very recently identified isomeric forms of $\beta-\mathrm{NAD}(\mathrm{P}) \mathrm{H}$ as substrates for renalase. These substrates arise from non-specific reduction of $\beta-N A D(P)^{+}$that forms $\beta-4-$ dihydroNAD(P) ( $\beta-N A D(P) H), \beta$-2-dihydroNAD(P) and $\beta$-6-dihydroNAD(P); the latter two being substrates for renalase. Renalase oxidizes these substrates with rate constants that are up to $10^{4}$-fold faster than any claimed for catecholamines. The electrons harvested are delivered to dioxygen via the enzyme's FAD cofactor forming both $\mathrm{H}_{2} \mathrm{O}_{2}$ and $\beta-\mathrm{NAD}(\mathrm{P})^{+}$as products. It would appear that the metabolic purpose of this chemistry is to alleviate the inhibitory effect of $\beta$-2dihydroNAD(P) and $\beta$-6-dihydroNAD(P) on primary metabolism dehydrogenase enzymes. The identification of this genuinely catalytic activity for renalase calls for re-evaluation of much of 
the research of this enzyme, in which definitive links between renalase catecholamine consumption and physiological responses were reported.

\title{
Keywords
}

Renalase, oxidase, catecholamine, Flavin, FAD, NAD.

\begin{abstract}
Abbreviations
HPLC, high performance liquid chromatography; FAD, flavin adenine dinucleotide; $\beta$-NADPH, reduced nicotinamide adenine dinucleotide phosphate; $\beta$-NADH (4DHNAD), reduced nicotinamide adenine dinucleotide; $\beta-\mathrm{NAD}^{+}$, oxidized nicotinamide adenine dinucleotide; 2DHNAD, 2-dihydronicotinamide adenine dinucleotide; 6DHNAD, 6-dihydronicotinamide adenine dinucleotide; NMR, nuclear magnetic resonance; $C D$, circular dichroism.
\end{abstract}

†This research was supported by a National Science Foundation grant to G.R.M (CHE-1402475) and by a University of Wisconsin-Milwaukee Research Growth Initiative Grant to G.R.M. 


\section{Introduction}

At the time of publication of this review, renalase has been known of and studied for a decade. During this period a clear divergence in the literature pertaining to renalase has developed. One line of investigation has attempted to establish and defend a link between renalase activity and catecholamine neurotransmitter oxidation in blood [1-5]. Another set of articles describe skepticism of this link and have offered well-reasoned arguments and experimental evidence that undermine it [6-10]. The preponderance of the renalase literature, however, pivots from passive acceptance of the catalytic link to catecholamines in blood and has pursued physiological consequences and correlations as indirect evidence of function (for a recent comprehensive review and analysis of such findings see Malyszko et al. 2014[10]).

The scientific conjecture surrounding renalase has led to an exponential accumulation of research articles and reviews since its discovery in 2005. The proliferation of renalase articles is founded on early reports that claim the protein is secreted by the kidney to lower blood pressure and slow heart rate by catabolizing circulating catecholamines, chiefly epinephrine and dopamine $[11,12]$. However, in vitro enzymological investigations of renalase chemistry have generally failed to observe activity with catecholamines (or any other substrate) $[9,13,14]$ and links between this proposed chemistry of renalase and its physiological function(s) have remained diffuse, often contrary and/or tenuous. This review attempts to offer a corrective summary of the renalase literature that is presented in the light of newly identified substrates for this enzyme. It is not intended to be a comprehensive chronology as recent scholarly synopses of the reported physiological and biochemical observations for renalase are available $[10,15][9]$. 


\section{Status Quo}

The current majority belief for the catalytic function of renalase is unsupported by experimental observation. The context for its role in nature was set askew by the very first observations made with this protein and these misconceptions continue to permeate the literature. The initial publication describing renalase claimed both to discover the enzyme and its catalytic function, a remarkable feat given a near infinite number of possibilities for potential

A

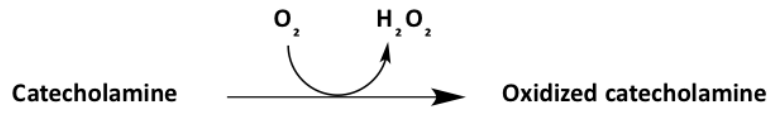

B

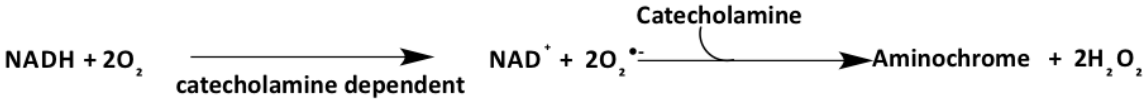

C<smiles>[X]NCC(O)c1ccc(O)c(O)c1</smiles>

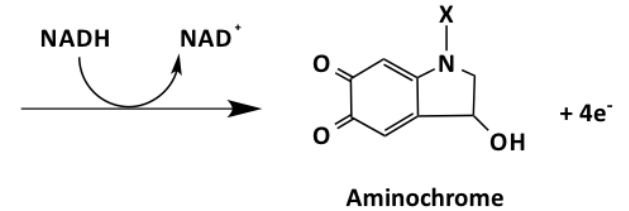

D
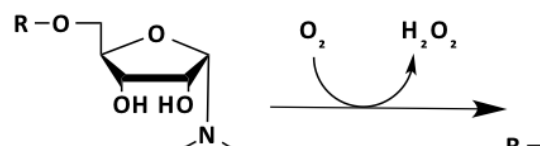

Aminochrome
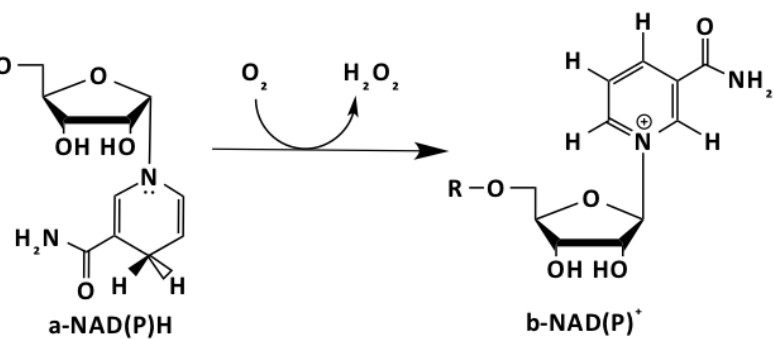

b-NAD(P)

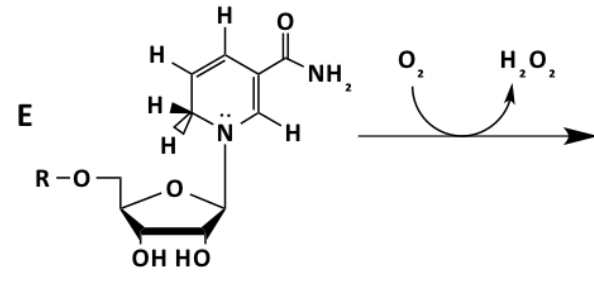

6DHNAD(P)
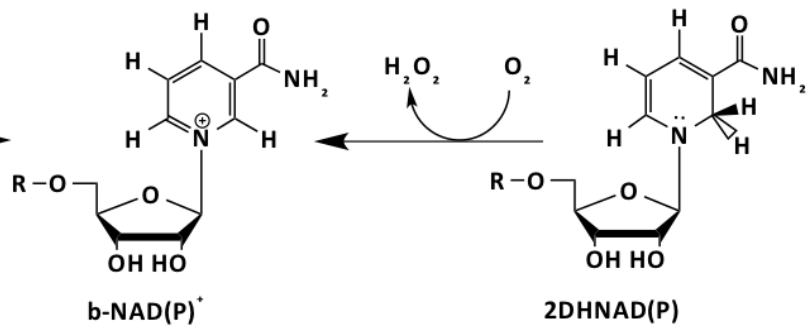

Scheme 1: Activities Claimed for Renalase in Chronological Order

substrates. This initial notion, that renalase is an enzyme/hormone that suppresses vascular tone, has largely confined the search for its catalytic function to the blood where, as it transpires, it is highly unlikely that renalase has a catalytic role. 
Renalase was identified by the Desir nephrology group at Yale School of Medicine. In the first report, renalase was proposed to be a kidney-derived hormone that consumes neurologically active catecholamines [11]. The partial basis for this assertion was that the renalase primary structure resembled (albeit poorly) that of monoamine oxidases (MAOs).
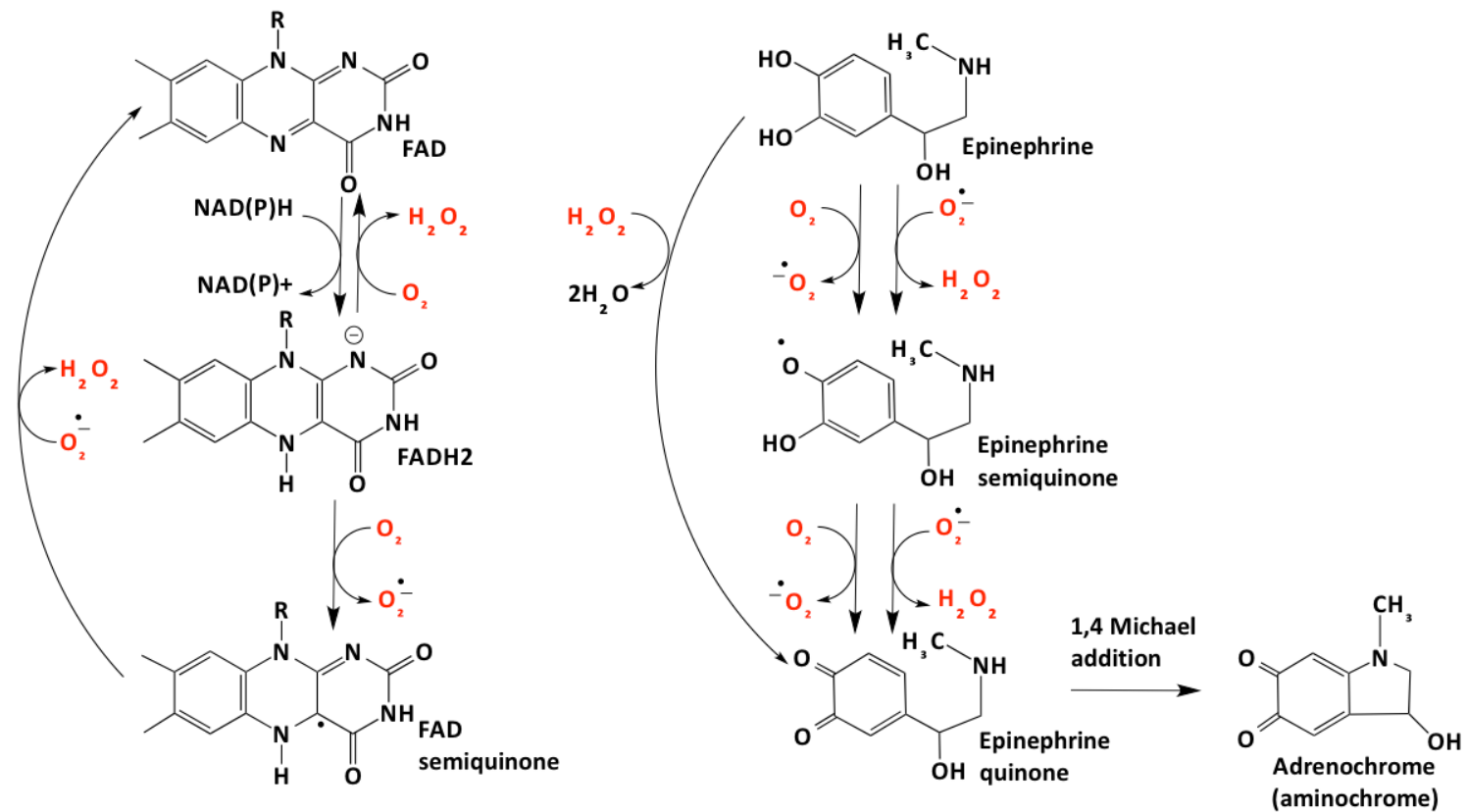

Scheme 2: The Autoxidation Chemistries of the Renalase Catecholamine Oxidase Assay (NB: species shown in red are capable of non-enzymatic oxidation of catecholamines)

When tested for activity with a number of catecholamines and primary amines using a generic Amplex Red hydrogen peroxide $\left(\mathrm{H}_{2} \mathrm{O}_{2}\right)$ detection assay, exceedingly low rates of $\mathrm{H}_{2} \mathrm{O}_{2}$ evolution were detected. The putative catecholamine substrates yielded 5-7-fold more $\mathrm{H}_{2} \mathrm{O}_{2}$ in the presence of renalase than did the primary amines and this was the basis for the substrate(s) identification. The difficulty with this claim was that no controls for (facile) autoxidation of these molecules were reported (Scheme 1A). This early assertion was then modified in subsequent reports to include $\mathrm{NAD}(\mathrm{P}) \mathrm{H}$ as a cosubstrate and it was proposed that the catecholamine substrate was oxidized by two electrons and cyclized to form molecules known 
as aminochromes that are neurologically inactive (Scheme 1B\&C)[1]. This was an unprecedented reaction in which an obligate two-electron reductant was required to oxidize the catechol by two-electrons. The stoichiometry of this transformation was not demonstrated and once again appropriate controls for the proposed chemistry were not reported [3].

The known propensity for autoxidation of catecholamines in the presence of molecular oxygen [16-18] dictates that control reactions must be employed and most particularly when the reported activity is low. Moreover, the reduction potential differences for the redox active molecules in the reaction ( $\mathrm{NADH}$ vs $\mathrm{FAD}, \Delta \mathrm{E}^{\mathrm{O}} 180 \mathrm{mV}$; $\mathrm{NADH}$ vs $\mathrm{O}_{2}, \Delta \mathrm{E}^{\mathrm{O}} 1130 \mathrm{mV}$; catechol vs $\mathrm{O}_{2}, \Delta \mathrm{E}^{\circ} \sim 430 \mathrm{mV}$ ) would yield non-specific production of $\mathrm{H}_{2} \mathrm{O}_{2}$ and superoxide from flavin hydroquinone autoxidation [19] and catechol autoxidation [20, 21] (see red species in Scheme 2). Non-specific production of such powerful oxidants would then promote further oxidation of catecholamines. It is reasonable to conclude that the abundance of non-catalytic facile exothermic reactions possible in the presence of $\mathrm{NAD}(\mathrm{P}) \mathrm{H}$, flavin adenine dinucleotide (FAD), catechol and $\mathrm{O}_{2}$ demands the use of control reactions in order to establish catalysis. As such it appears at least probable that the foundational observations for renalase activity were scientifically deficient. The inadequacy of these initial activity claims has been clearly stated in the literature $[6,14,22]$. Moreover, in 2010, Pandini et al. reported that renalase yielded no added $\mathrm{H}_{2} \mathrm{O}_{2}$ production in the presence of catecholamines when compared to the appropriate controls [23] and this same group later showed that $\mathrm{NAD}(\mathrm{P}) \mathrm{H}$ does not contribute to catecholamine consumption either [9]. Despite these apparently sound refutations, the majority of renalase researchers continue to publish under the assumption that catecholamine catabolism is the function of this enzyme $[1,3-5,12,15,24-50]$. 


\section{Gene and Isoforms}

The renalase gene was identified from a survey of the 2003 mammalian gene project library. Gene products were selected for secretory sequences, a general lack of homology with known proteins and a predicted lack of membrane association. Northern blot analysis for a range of human tissues identified a single transcript with high abundance in kidney cells. Alignment revealed a gene that resides on chromosome 10 and spans 309,462 bp. The open reading frame of the primary spliced transcript coded for a 342 amino acid protein with a predicted mass of $37.8 \mathrm{kDa}$. Motifs for an N-terminal signal peptide, a dinucleotide binding domain, and an oxidase-like domain were reported. Northern blot analysis also indicated additional transcript lengths suggesting multiple renalase splicoforms [11].

The renalase gene structure was first reported to have nine exons [11]. Later the gene was claimed to be comprised of ten exons that could yield as many as nine isoforms [28]. One year later the same group reported that there are four primary renalase transcripts formed from just seven exons [51]. Most recently, the same group has returned to the ten-exon structure that now is said to yield seven isoforms (though the fifth exon was not incorporated into any of the isoforms proposed) [52]. Each of these reports do not contextually cite the prior, and so the literature does not include the experimental lineage or an argument for the various exon and isoform arrangements. A comprehensive account of the gene structure, isoforms, and single nucleotide polymorphisms was recently provided in a review by Baroni et al.[9]. In this description the gene is comprised of eleven exons; two N-terminal, six internal and three Cterminal exons (Figure 1). 


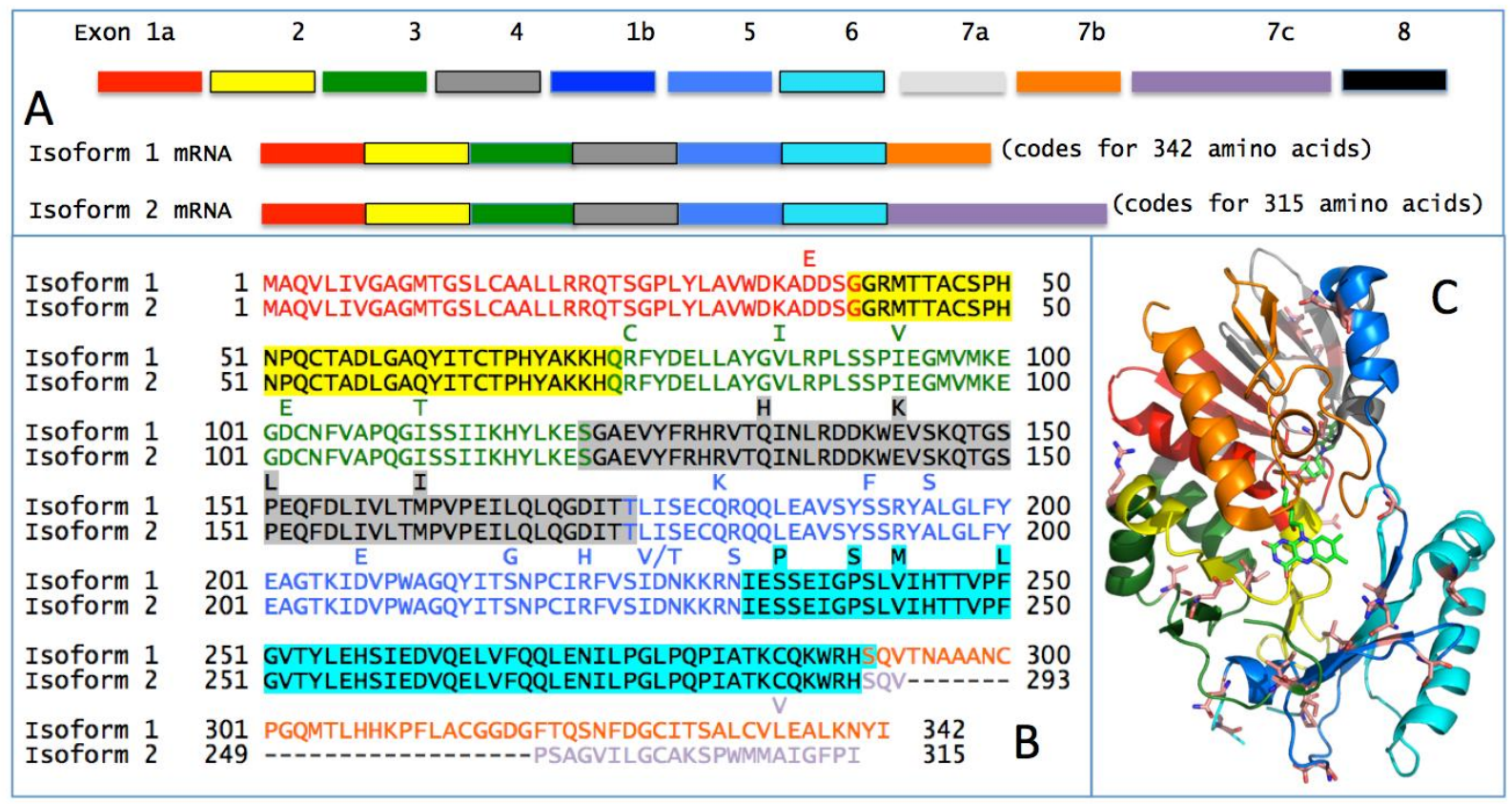

Figure 1. Renalase Gene and Isoform Structure. A. Schematic sequential representation of the renalase gene exons. Exons designated with a 1 form $\mathbf{N}$-termini and those with a $\mathbf{7}$ form $\mathrm{C}$-termini. Exon composition of the two dominant isoform mRNA shown below. B. Sequence alignment of renalase isoforms 1 and 2. Amino acid substitutions arising from single nucleotide polymophisms (SNPs) are show above the sequence. C. The fold of renalase colored according exon origin. Residues subject to change by SNPs are rendered as sticks.

What appears to be constant and verified by cDNA sequence is that there are two dominant isoforms of renalase each coded for by mRNA assembled from seven exons (Figure 1). Isoform 1 is coded by a 1477 bp transcript (NM_001031709.2) and yields a protein of 342 amino acids and variant 2 is coded by a 2107 bp transcript (NM_018363.3) that yields a truncated protein of 315 amino acids. Isoform 2 is derived from swapping only the exon that codes for the C-terminus. All other proposed isoforms eliminate sequence elements that are now understood to comprise the renalase active site and/or FAD binding domain [13] (see below). As such, other proteins that are potentially derived from the renalase gene are unlikely to harbor the catalytic function(s) now attributable to the isoform 1 variant.

\section{Tissue Distribution}


Renalase isoform 1 was originally reported to be predominantly expressed in the proximal tubes and glomerulus of the kidney, but was said to be detectable in cardiac muscle, liver tissue and skeletal muscle [11] and the bias for higher expression in the kidney was later confirmed [53]. However, it has since been shown that isoform 1 transcripts are detectable in nerves, adrenal glands, adipose tissue [51], and that expression is prominent in reproductive tissues [54]. Moreover, the Proteomics DB database reports widespread tissue distribution of renalase isoforms 1 and 2 [55]. Collectively these reports suggest that renalase expression is quite systemic. Though monoclonal antibody detection indicates circulating concentrations of $\sim 4 \mu \mathrm{g} / \mathrm{mL}(100 \mathrm{nM})$, it is of note that despite its claimed hormone function, no convincing evidence of renalase catalytic activity in blood has yet been offered [42]. Moreover, there is limited evidence that renalase is actively secreted or that the $\mathrm{N}$-terminal signal sequence is functioning as a secretion directive. The residues that constitute the putative secretory signal (1-17) form elements of buried secondary structure that are required to bind the FAD cofactor of the enzyme $[9,11,13]$.

There is a general lack of data describing renalase isoform 2. In the discovery article, Xu et al. reported a $2.4 \mathrm{~kb}$ renalase transcript that was prominent in skeletal muscle, similar to the the $2.1 \mathrm{~kb}$ transcript that codes for isoform 2 (see Figure 1) [11]. This suggests that the two dominant isoforms may have discrete functions and locales. A variant 2 gene has been constructed, cloned and expressed heterologously in bacteria though no activity for this protein has yet been reported nor is it known if it has FAD bound [56].

\section{Expression and/or Purification of Renalase}


The enzymological or chemical investigation of renalase has lagged the reports of physiological associations. This has meant that the majority of the literature pertaining to this protein is based on correlations made prior to a foundational understanding of its catalytic function. In addition, renalase preparations are typically used without a sample integrity standard and so all preparations are by default regarded as functional [11, 12, 24]. Early attempts to observe activity used renalase purified from urine using anti-renalase affinity chromatography or an $\mathrm{N}$-terminal glutathione-S-transferase fused renalase followed by glutathione affinity chromatography $[2-4,11,27]$. As stated above, these forms of renalase were only tested for $\mathrm{H}_{2} \mathrm{O}_{2}$ production in the presence of catecholamines and primary amines and largely without appropriate control reactions and as such have not been shown to be active. In 2010, Pandini et al. completed an

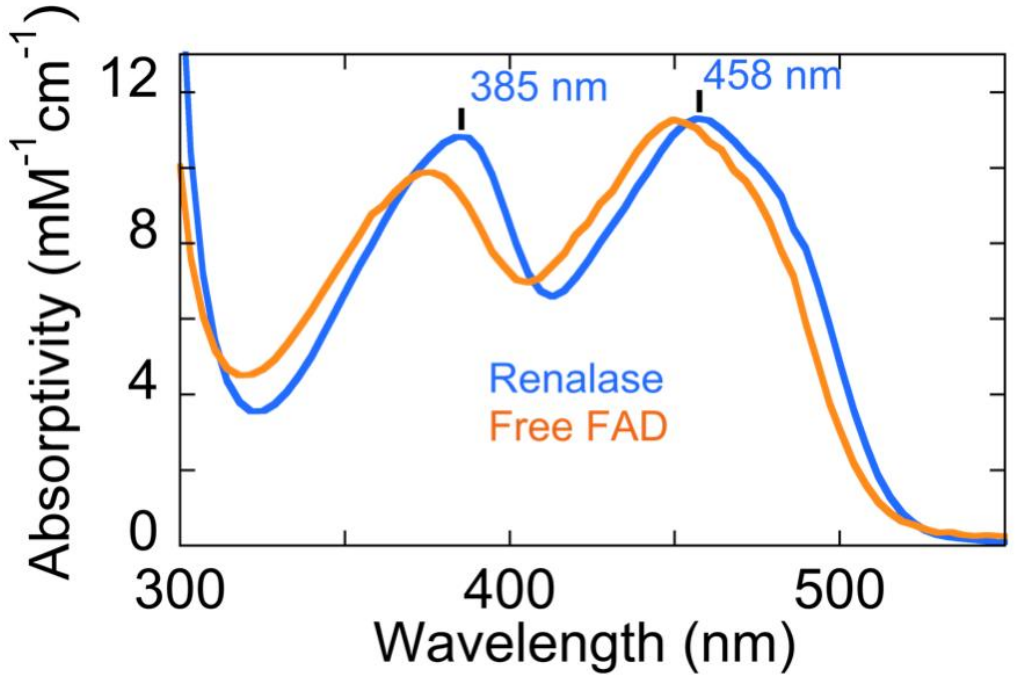
extensive investigation of Figure 2. The Characteristic Absorption Spectrum of Renalase. The flavin absorption spectrum of renalase (blue) compared to that of unbound FAD (orange).

renalase heterologous expression in Escherichia coli [23]. In this study it was found that the enzyme could be expressed most effectively at low temperature $\left(16{ }^{\circ} \mathrm{C}\right)$ from an $E$. coli codon usage optimized gene cloned into a T7 RNA-polymerase based expression plasmid in which the protein becomes fused to either an N-terminal (6-) His-tag or SUMO-tag. Purification was achieved by nickel-sepharose affinity chromatography. Though the catalytic function was 
unknown at the time of publication, these authors offered the first spectrophotometric evidence of what are now known to be the characteristic flavin absorption maxima of renalase; 385 and $458 \mathrm{~nm}$ cf. free FAD 378 and $450 \mathrm{~nm}$ (Figure 2). This form of renalase was ultimately crystalized and the X-ray structure solved [13]. That this structure was populated with FAD and had a fold similar to numerous redox active flavoproteins was a sound indication that this was the native form of the enzyme. Desir et al. later used a $E$. coli codon optimized human renalase gene in a $\mathrm{T7}$ expression system to express the renalase peptide at $37{ }^{\circ} \mathrm{C}$ [2]. This expression method yielded $\sim 95 \%$ inclusion body protein. It was found that solubilization in urea followed by dilution in the presence of $F A D$ at $\mathrm{pH} 10.5$, slow adjustment of the $\mathrm{pH}$ to 8.2 and extensive dialysis produced a soluble protein. This refolding method was tested by Beaupre et al. and shown to produce a soluble, stable FAD-associated protein without the characteristic renalase flavin absorption maxima and none of the activity now associated with the enzyme (see below), suggesting that this refolded form of renalase does not acquire the native tertiary structure [14].

\section{Renalase Structure}


The three dimensional structure of renalase isoform 1 was solved in 2011 to $2.5 \AA$ by the Aliverti group at the University of Milan (PDB ID 3QJ4) and this remains the only verified renalase structure [13]. It is of note that the human structure was solved and refined using molecular replacement based on the coordinates of a remarkably similar protein from Pseudomonas phaseolicola (reported as syringae; PDB ID 3KKJ). The renalase structure has $\sim 50 \% \alpha / \beta$ secondary structure and is elongated with a cleft running perpendicular to the long axis at the interface of two domains. The topology observed was that known to a variety redoxactive flavoproteins of which para-hydroxybenzoate hydroxylase (PDB ID 1PBE) is the paradigm

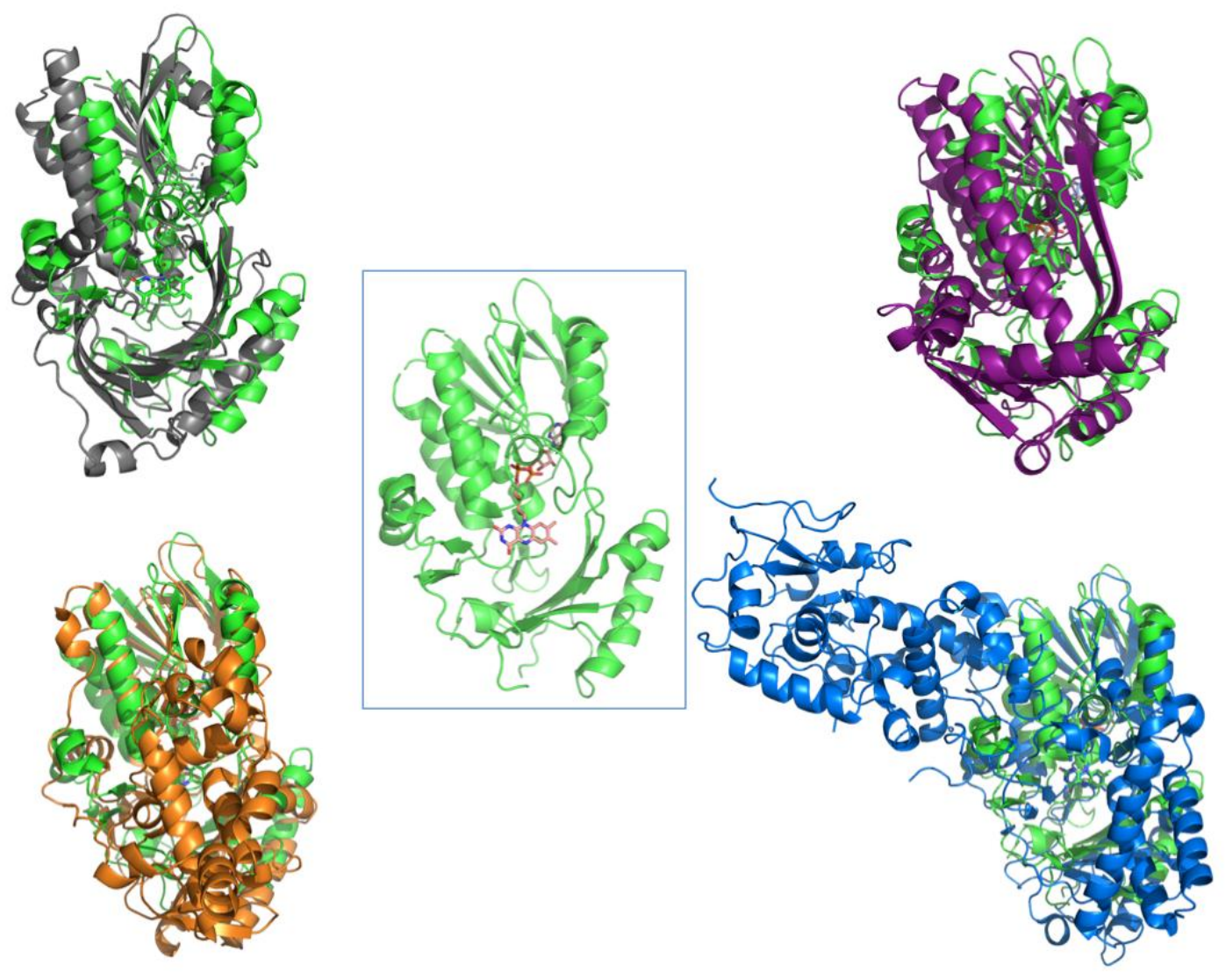

Figure 3. The Fold of Renalase Structurally Aligned with Enzymes of Similar Topology. Renalase is shown in green, monoamine oxidase $B$ is shown in orange, D-amino acid oxidase is depicted in grey, lysine-specific histone demethylase is blue and para-hydroxybenzoate hydroxylase is shown in violet. 
[57]. Other proteins that have similar topologies and folds include protoporphyrinogen oxidase (PDB ID 3LOV), D-amino acid oxidase (PDB ID 1KIF), L-amino acid oxidase (PDB ID 2JB2), Lysspecific histone demethylase (PDB ID 2UXX) and monoamine oxidase B (PDB ID 1GOS)[57-62]. Figure 3 includes three-dimensional structural alignment of the renalase tertiary structure with a selection of these proteins. Unlike monoamine oxidase enzymes, the renalase structure lacks an additional domain and as a consequence the active site is exposed to solvent. With the exception of MAO enzymes, all members of this family bind the FAD non-covalently and anchor the interaction at the adenosine end of the cofactor by association with a Rossmann fold. Each member of this structural family has a unique constellation of conserved residues surrounding the isoalloxazine of the FAD cofactor consistent with inimitable functions [63]. In renalase the xylene ring of the FAD isoalloxazine is partially occluded by Trp288 but the pyrimidine ring is solvent exposed in what is a rather conspicuous surface concavity (Figure 4). Milani et al. correlated conserved identity and similarity and proposed that the active site was roughly divided into aromatic and non-aromatic hemispheres [13]. The aromatic opening to the active site has three phenyl/phenol side chains (Tyr62,214 and Phe223). The non-aromatic half of the active site forms the inner surface of the cavity more proximal to the xylene moiety of the FAD isoalloxazine. The conserved portion of this surface is supplied by Gln292, $\operatorname{Arg} 193$, His245 and Arg222 and as such creates overall positive electrostatic environment (Figure 4). 


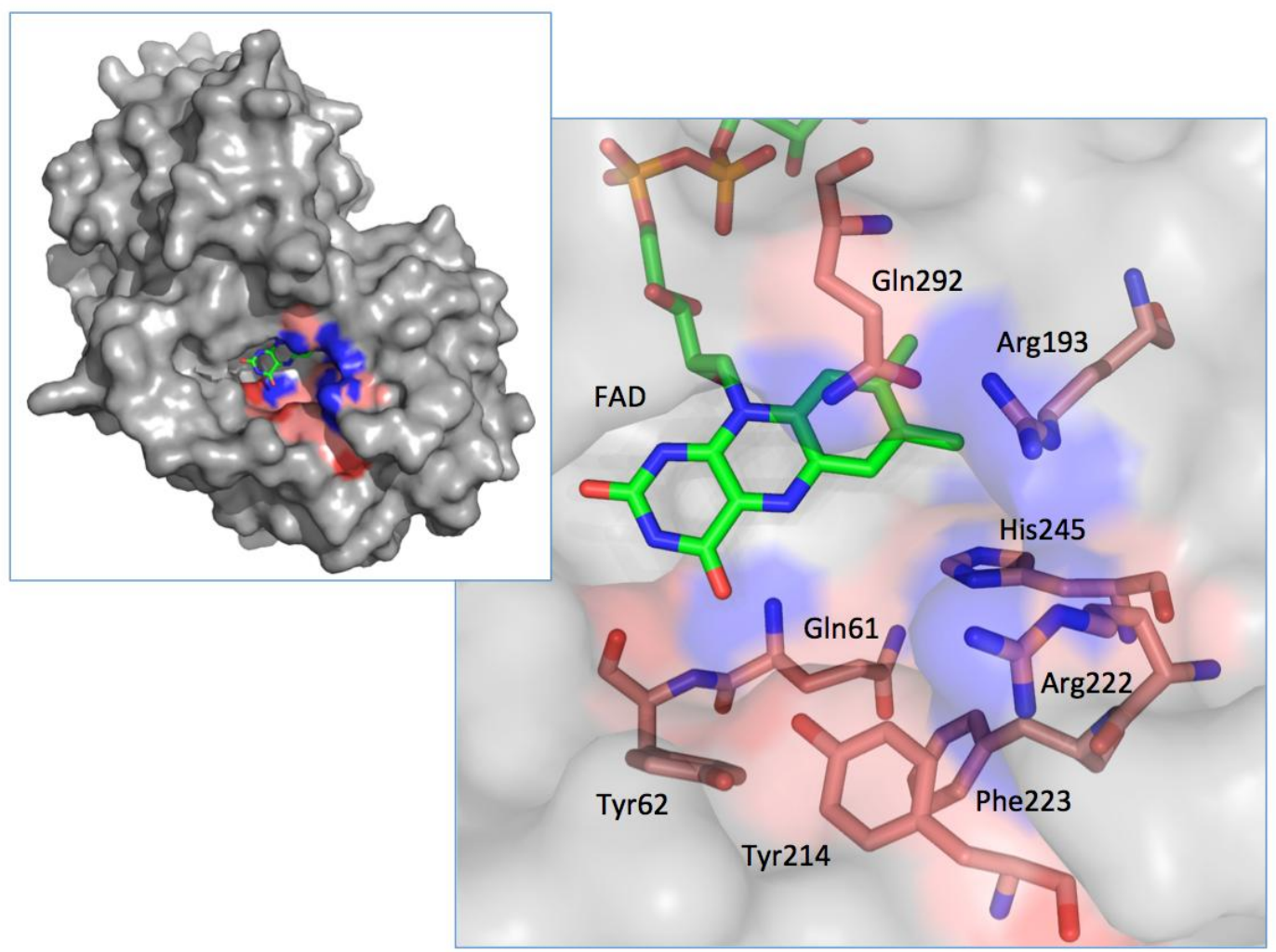

Figure 4. The Active Site Cavity of Renalase. The inset depicts the solvent accesible surface of renalase with the exposed flavin. The primary figure shows conserved active site residues relative to the flavin isoalloxazine moiety.

One of the criteria that led to the identification of renalase was a putative secretory signal sequence at the N-terminus (residues 1-17) with a low SignalP score of 0.4 [11]. The structure of renalase reveals that this sequence includes parts of the protein that interact with the adenine end of the FAD cofactor, in particular it forms part of the Rossmann fold. This indicates that it is unlikely that the enzyme could retain its function if this $\mathrm{N}$-terminal section were to be unraveled and/or cleaved. The structure of renalase affords an opportunity to map the changes that occur with single nucleotide polymorphisms (SNPs). In Figure 1 we see that SNP base changes that result in amino acid substitutions are scattered throughout the $\mathrm{N}$ terminal $70 \%$ of the protein code and noticeably absent from the remainder. Roughly half of the side chains altered by SNPS are found on external surfaces of renalase and 11/23 involve 
conservative amino acid changes. A number of SNPs have been associated with medical abnormalities [31], but only the D37E variant has been studied in vitro and prior to the newly identified activity we describe below. However, the slow NADH oxidase-diaphorase activity for

this variant was shown to have a $\mathrm{K}_{\mathrm{m}}{ }^{\mathrm{NADH}}$ that is 24 -fold higher and a $\mathrm{k}_{\text {cat }}$ diminished by half compared to wild-type [29]. Now that a genuinely catalytic substrates for renalase have been identified, in vitro examination of each SNP variant can be made and correlated with population associations for specific maladies.

\section{Early Renalase Preparations and Physiological Affects}

That no verified substrate for renalase was known for ten years, meant that routine verification of sample integrity by activity assay was not possible. In a worst-case scenario it is conceivable that the majority of physiological testing has been carried out with inactive enzyme. A very extensive survey of renalase heterologous expression identified the conditions required to yield soluble enzyme [23]. This was the first study in which the now characteristic renalase flavin absorption spectrum was depicted, indicating both an increase in the absorption intensity of the $380 \mathrm{~nm}$ transitions and 7-8 $\mathrm{nm}$ red shifts in both visible light maxima compared to those of FAD in solution (Figure 2). One year later, the same group published the X-ray crystal structure of renalase expressed in this manner. That this structure exhibited a known fold common to numerous redox active flavoproteins was, until recently, the most convincing evidence of functional renalase production [13]. A variety of other reportedly successful expression methods can be found in the literature. However, these studies include no biochemical analysis of the expression product. The conspicuous nature of the yellow color of 
the FAD cofactor is generally reported in the form of an absorption spectrum when observed bound to a protein. That these studies do not describe the color of the protein or offer an absorption spectrum as evidence suggests that they were unsuccessful in obtaining natively folded renalase. By way of example, the Aliverti group have reported that the purified GSTrenalase fusion product, one of the forms isolated in the progenitor article, contains no FAD $[9$, 11]. Given the success of this group in expression of natively folded renalase along with independent verification of their expression protocol by Beaupre et al., the characteristic absorption maxima for the flavin of renalase should be taken as evidence of correctly folded enzyme (Figure 2) $[14,23,64]$. All reports that do not include this basic criterion are made without proof of a functional sample and should be evaluated as such.

The majority of renalase researchers now accept that renalase consumes catecholamine neurotransmitters, and have often pursued physiological correlations predicated on that belief $[1,3-5,12,15,24-50]$. The primary and somewhat justifiable reason for this is the observation that renalase is apparently capable of influencing blood pressure. In the discovery article Xu et al., observed a dose dependent, almost immediate and pronounced (limit around 40\%) decrease in systolic and diastolic pressure in naturally hypertensive Sprague-Dawley rats after arterial renalase injection [11]. While the affect abated within 4 minutes, it was later shown that this response could be prolonged by subcutaneous injection [1]. The initial observations were confirmed in subsequent reports that indicated increases in blood pressure could be induced by renalase gene knockout and by renalase antisense RNA [4, 65]. It is of value to note that the renalase knockout described by Wu et al., was made in C5BL/6 mice. The knockout mouse was reported to have $5-12 \%$ increases in blood pressure compared to the $\mathrm{C} 5 \mathrm{BL} / 6$ 
wildtype and a much greater degree of myocardial tissue damage following an ischemic event $[4,5,26]$. However, it was indicated by Eikelis that the wildtype C5BL/6 mouse does not produce a form of renalase that is capable of binding FAD as the renalase gene product coded by this strain is truncated at the $\mathrm{N}$-terminus [22]. Ironically, this apparent oversight, provides added evidence that renalase catalytic activity is not related to mammalian pulmonary function.

\section{The Quest for a Substrate}

Even with the benefit of operonic or regulatory genetic context, the identification of a substrate for an enzyme is a daunting proposition. Furthermore, sequence is not a reliable predictor of function as even small primary structure alterations can alter the substrate specificity or, in rare cases, even the class of the reaction catalyzed [66]. Conversely, proteins with very low or no identity can have the same catalytic function. Renalase is frequently referred to as MAO C, the third mammalian oxidase to consume catecholamines $[1,12,67]$. The similarity of renalase to MAOs is overall low (13-17\%) and the identities are primarily clustered toward the $\mathrm{N}$-terminus [13]. Despite this lack of similarity $\mathrm{Xu}$ et al. quite reasonably tested renalase for catecholamine oxidase activity due to the observation that injected renalase lowered blood pressure. However, the Amplex Red assay used detects only $\mathrm{H}_{2} \mathrm{O}_{2}$ indicative of oxidation in which dioxygen is the oxidant but does not by itself establish catalysis or identify the reductant substrate (Scheme $1 \mathrm{~A}$ ). This assay indicated a modicum of $\mathrm{H}_{2} \mathrm{O}_{2}$ production in the presence of catecholamines. This initial observation by the group that discovered renalase has had a seminal influence that has largely limited the search for the substrate(s) of renalase to molecules known to exist in blood and/or to influence vascular tone. The first independent 
verification of the direct hemodynamic influence of renalase was made by Pandini et al., who observed $10-30 \%$ decreases in blood pressure of Sprague-Dawley rats when renalase was introduced at a dose of $4 \mathrm{mg} / \mathrm{Kg}$ (1000-fold greater than constitutive basal blood concentrations determined by enzyme linked immunosorbent assay) [23, 42].

Together, the above observations are the foundation of the association of renalase, catecholamines and vascular tone. Practices such as the use of non-specific $\mathrm{H}_{2} \mathrm{O}_{2}$ detection as the sole measure of renalase activity further continue to conflate this association with renalase catalysis. Using this assay, the Desir group have reported extremely low renalase activity in blood plasma, and relative high activity in urine. However, an infusion of epinephrine or dopamine $(\sim 5-10 \mu \mathrm{M})$ to the blood stream brought about a rapid $(<1 \mathrm{~min})$ increase in $\mathrm{H}_{2} \mathrm{O}_{2}$ production that was not mirrored by the quantity of renalase detected (by antibody). This resulted in the conclusion that under basal conditions in blood renalase is in some way inhibited and that this quiescent or "prorenalase" form becomes activated in the presence of specific catecholamines [27]. This proposal appears somewhat at odds with prior reports where injected renalase has a marked and sustained affect on blood pressure, apparently not inhibited by contact with blood $[11,23]$.

The general difficulties in the generic assay methods used to measure renalase activity are described above. The facile oxidation of catecholamines and their capacity to conduct oneelectron chemistry imparts inevitability to their oxidation in solutions equilibrated with dioxygen, resulting in the non-enzymatic production of $\mathrm{H}_{2} \mathrm{O}_{2}$ (Scheme 2). Moreover, the exceedingly slow rates reported for renalase activity $\left(0.004 \mathrm{~s}^{-1}\right)$ using these methods has been repeatedly suggested to be evidence that what is being observed is non-enzymatic $[6,8,22]$. 
Morover, the only study to use appropriate controls to delineate potential renalase activity from background catecholamine oxidation concluded that renalase was not active with such molecules [23].

$\mathrm{NAD}(\mathrm{P}) \mathrm{H}$ has also been proposed as the cosubstrate for renalase. Prior to the publication of the renalase structure, the Desir group surmised that the GXGXXG motif of the Nterminal Rossman fold could be employed by renalase to bind nicotinamide dinucleotide substrates [29]. In the subsequent year the structure of renalase was reported, and it was found that the Rossman fold was solely utilized to bind the adenosine moiety of FAD [13]. Desir et al. reported a marked increase in renalase mediated $\mathrm{NADH}$ oxidation and $\mathrm{H}_{2} \mathrm{O}_{2}$ production in the presence of epinephrine and NADH [2] (Scheme 1B) and soon after proposed that the product of the reaction was an aminochrome (Scheme 1C) [1]. These observations were not reconciled with the early reports for renalase activity where $\mathrm{NAD}(\mathrm{P}) \mathrm{H}$ was not included as a cosubstrate [11]. It was proposed that renalase preferentially used NADH to reduce the flavin cofactor in order to deliver electrons to molecular oxygen generating superoxide anion in a diaphorase-type reaction. This activity was reported to be entirely dependent on the presence of catecholamines to the point that the reduced flavin will not react with dioxygen in the absence of these molecules [2]. The evidence offered for this reaction was that superoxide dismutase (SOD) could completely abolish epinephrine dependent NADH oxidation by renalase.

The difficulty with this proposal is that it suggests that the superoxide anion is the entity active in the oxidation of catecholamines, while also holding that superoxide is released from renalase (such that it can be disproportionated and nullified by SOD) and that $\mathrm{H}_{2} \mathrm{O}_{2}$ is a product of the reaction. Such a proposal only holds if we accept both that the superoxide anion acquires 
purpose where, after being released from the active site, it reacts only with specific catecholamines and also that it exists in solution long enough to do so [68]. In the same article Desir et al., suggests that $\mathrm{H}_{2} \mathrm{O}_{2}$ plays no significant role in the oxidation of catecholamines but (apparently) remains a product of the enzyme chemistry. The complexity of this proposal is irreconcilable with known chemistry. The net proposed reaction is that renalase preferentially binds and oxidizes NADH. In the presence of specific catecholamines the renalase flavin then supplies one electron to dioxygen forming a superoxide anion (and a flavin semiquinone). The superoxide is then released from the active site but reacts only with a catecholamines to become further reduced by one electron forming $\mathrm{H}_{2} \mathrm{O}_{2}$ and the catechol semiquinone. Presumably, the one-electron reduced forms of the flavin and the catecholamine quinone enter a second cycle of dioxygen reduction, to yield the two electron oxidized flavin and the catecholamine quinone (and ultimately aminochrome). This illustrates that considerations of reaction stoichiometry, clear evidence of catalysis, and good chemical intuition must guide claims for enzyme activity.

The Aliverti group also examined the diaphorase activity of renalase and were able to confirm that renalase catalyzes a slow reaction with both $\mathrm{NADH}$ and NADPH with an apparent preference for NADH [13]. Turnover could be induced in the presence of artificial electron acceptors which yield kinetic parameters of $k_{c a t}=0.002-0.004 \mathrm{~s}^{-1}, \mathrm{~K}_{\mathrm{m}}{ }^{\mathrm{NADH}}=18 \mu \mathrm{M}, \mathrm{K}_{\mathrm{m}}{ }^{\mathrm{NADPH}}=175$ $\mu \mathrm{M}$, overall similar to those reported by Desir et al [2]. In addition, Alverti's group were able to show that the FAD cofactor becomes reduced under anaerobic conditions when incubated with $\mathrm{NAD}(\mathrm{P}) \mathrm{H}$ and that this reduction reaction was the primary rate limiting process. Unlike the Desir group however, Aliverti rightly concluded that this was a predictable slow side-reaction that did 
not indicate that $\mathrm{NAD}(\mathrm{P}) \mathrm{H}$ molecules were substrates, but instead a consequence of the rather cavernous active site, the exposed isoalloxazine of FAD and the thermodynamic capacity of $\mathrm{NAD}(\mathrm{P}) \mathrm{H}$ to reduce FAD (Figure 4, Scheme 2).

In initial efforts to verify or refute the above observations, our group investigated the interaction of renalase with $\mathrm{NAD}(\mathrm{P}) \mathrm{H}$ molecules. We observed that under anaerobic conditions the renalase FAD became rapidly $\left(\sim 40 \mathrm{~s}^{-1}\right)$ fractionally reduced in the presence of excess $\mathrm{NAD}(\mathrm{P}) \mathrm{H}$ and that a large excess could bring about complete reduction. The conclusion was that a contaminant molecule in the NADPH solution was a substrate for renalase. A plot of the concentration of NADPH added versus the concentration of reduced renalase indicated that the NADPH solution contained a $1.3 \%$ contaminant that reacted rapidly $\left(10^{4}\right.$-fold faster than prior substrate claims) $[14,69]$. Similarly, NADH solutions harbored a $4 \%$ contaminant molecule(s) that also reduced the FAD cofactor rapidly. Both of these contaminant molecules induced multiple turnovers when added in excess to the enzyme concentration and the reduced flavin cofactor delivered the electrons harvested to dioxygen to produce $\mathrm{H}_{2} \mathrm{O}_{2}$ with a 1:1:1:1 stoichiometry. Using NMR and HPLC the product of the reaction was identified as $\beta-N A D(P)^{+}$. These observations led to the conclusion that renalase was an oxidase whose function was to recycle molecules that are derived from $\beta-N A D(P) H$ aqueous speciation. HPLC permitted separation of the active component(s) from the background of $\mathrm{NAD}(\mathrm{P}) \mathrm{H}$ molecules. These substrate components were fleeting, and tended to decay within minutes. The absorption spectrum of the substrate had a $345 \mathrm{~nm}$ maximum indicating alterations in the dihydropyridyl ring of the $N A D(P) H\left(\beta-N A D(P) H \lambda_{\text {max }}=340 \mathrm{~nm}\right)$. The observed absorption maximum, extinction coefficient $\left(\varepsilon_{345 \mathrm{~nm}}=6580 \mathrm{M}^{-1} \mathrm{~cm}^{-1}\right)$ and aqueous equilibrium accumulation $(1.3 \%-\mathrm{NADPH}, 4 \%$ - 
$\mathrm{NADH})$ compared well with those reported for $\alpha-\mathrm{NAD}(\mathrm{P}) \mathrm{H}$ molecules $\left(\lambda_{\max }=345 \mathrm{~nm}, \varepsilon_{345 \mathrm{~nm}}=\right.$ $6170 \mathrm{M}^{-1} \mathrm{~cm}^{-1}$, aqueous equilibrium fractions: $1.5 \%-\mathrm{NADPH}, 10 \%-\mathrm{NADH}$ ) [70-72]. This led to the initial conclusion that renalase was recycling $\alpha$-anomers of $N A D(P) H$ molecules to form $\beta$ $\mathrm{NAD}(\mathrm{P})^{+}$to avoid loss of cellular redox currency in the form of $\alpha-\mathrm{NADP}^{+}$; a molecule with no known function in mammalian metabolism (Scheme 1D).

Structural assignment of the substrate molecule(s) was made very recently. We have found that the fleeting nature of this molecule(s) could be slowed in solutions of pure $\mathrm{D}_{2} \mathrm{O}$ and that salts and buffers tended to accelerate the loss of the substrate(s). A combination of mass spectrometry, homonuclear, heteronuclear, and heteronuclear multibond NMR coupling was used to identify the $345 \mathrm{~nm}$ species. This species was found to be 6-dihydroNAD(P) (6DHNAD); an isomeric form of $\beta-\mathrm{NAD}(\mathrm{P}) \mathrm{H}$ that is reduced in the 6-position rather than the native 4position of the nicotinamide ring (Scheme 1E)[69]. Such molecules arise from non-specific reduction of $\beta-N A D(P)^{+}$. Reduction of $\beta-N A D(P)^{+}$using a strong reductant such as sodium borohydride yields three products, $\beta-N A D(P) H, 6 D H N A D(P)$ and a third product with an absorption maximum of $394 \mathrm{~nm}$. It was shown that both the $6 \mathrm{DHNAD}(\mathrm{P})$ and the species with the $394 \mathrm{~nm}$ absorption maximum were substrates for renalase and that both were oxidized to yield $\beta-\mathrm{NAD}(\mathrm{P})^{+}$and $\mathrm{H}_{2} \mathrm{O}_{2}$ as products. Structural assignment of the second substrate identified 2-dihydroNAD(P), the product formed when $\beta-N A D(P)^{+}$is reduced at the alternate ortho position with respect to the nicotinamide pyridyl nitrogen (Scheme 1E).

Though not initially structurally assigned, non-specific products of $\beta-N A D(P)^{+}$reduction had been described throughout the mid-1950's and 60's [73-78]. It was known that these alternate reduction products were non-reactive with dehydrogenase enzymes, but it was Lowry 
et al., and Dalziel that showed that these molecules were inhibitory to lactate dehydrogenase $[79,80]$ and this was verified in later work [81]. We surmised that if $6 D H N A D(P)$ and/or 2DHNAD(P) were inhibitory to primary metabolism dehydrogenase enzymes, renalase would have a metabolic purpose; the oxidation of $\beta-\mathrm{NAD}(\mathrm{P}) \mathrm{H}$ isomers in order to alleviate inhibition of respiratory activity. We tested both 6DHNAD and 2DHNAD as inhibitors for malate dehydrogenase, lactate dehydrogenase and lipoamide dehydrogenase. These data indicated that these isomeric forms of $\beta-N A D(P) H$ posed a significant threat to primary metabolism exhibiting $K_{\mathrm{I}}$ values for specific primary dehydrogenases in the nMolar range [69].

\section{Biochemical Properties of Renalase}

The first biophysical descriptions of renalase were provided with the initial articles published by the Alverti group. These reports described optimization of renalase expression [23] and the structure of the enzyme [13]. In these studies the renalase FAD cofactor was used as a spectrophotometric reporter to examine specific properties. It was shown that the normally fluorescent FAD cofactor was largely quenched in the renalase active site and visible light circular dichroism (CD) indicated a uniquely asymmetrical environment for the isoalloxazine. The ultra-violet region of the $C D$ spectrum suggested roughly half of the primary structure was committed to $\alpha / \beta$ secondary structure. Dynamic light scattering confirmed a globular tightly packed protein, and this was confirmed by the observation that renalase is highly resistant to proteolysis and thermal denaturation (transition at $54{ }^{\circ} \mathrm{C}$ ) $[9,23]$. Milani, et al.

reported that the renalase flavin readily formed an equilibrium adduct with sulfite $\left(\mathrm{K}_{\mathrm{d}}^{\mathrm{SO}}=1.8\right.$ $\mathrm{mM})($ Scheme 3), a curious characteristic common to many flavin-dependent oxidase enzymes 
(and potentially another simple means to verify renalase preparations). In the same article it was reported that $\beta-\mathrm{NADP}^{+}$and $\beta-\mathrm{NAD}^{+}$formed weak complexes with renalase $\left(\mathrm{K}_{d}^{\mathrm{NAD}}=2.2 \mathrm{mM}\right.$, $\mathrm{K}_{d}^{\text {NADP }}=1.6 \mathrm{mM}$ ) that perturbed the FAD spectrophotometric characteristics, suggesting close association with the cofactor [13]. Though not known at the time of publication, these titrations measured product complex affinity for the

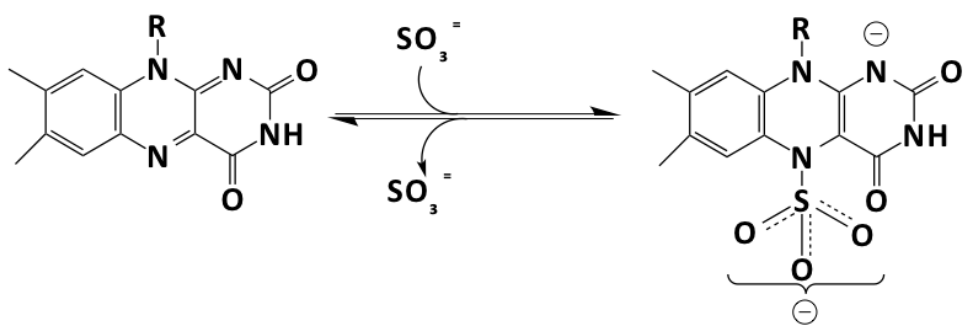
Scheme 3: Flavin Dependent Enzyme Sulfite Adduct Equilibrium oxidized form of the enzyme [69].

Very recently we reported two substrates for renalase that induce genuinely catalytic behavior. 2- and $6 \operatorname{DHNAD}(\mathrm{P})$ are both rapidly oxidized by renalase yielding a complex of reduced FAD cofactor and $\beta-N A D(P)^{+}$that then reacts with molecular oxygen producing $\mathrm{H}_{2} \mathrm{O}_{2}$ and dissociates $\operatorname{NAD}(P)^{+}$. In a series of three articles that initially misidentified the substrate(s), our group has characterized the catalytic cycle of renalase in turnover with 2- and 6DHNAD. Using primarily transient kinetic methods and static titrations with ligands, all salient features of the catalytic cycle are now known (Scheme 4). For simplicity Scheme 4 depicts the catalytic cycle of renalase with 6DHNAD. However, renalase is reactive with the 2-and 6-dihydro forms of $\beta$-NAD and presumably $\beta$-NADP [14]. Renalase associates rapidly with either 2DHNAD or 6DHNAD forming a $\operatorname{Ren}_{\mathrm{ox}} \bullet \beta-\mathrm{XDHNAD}$ complex that has a dissociation constant of $\sim 170 \mu \mathrm{M}$ for both isomers. The enzyme then catalyzes the transfer of a hydride equivalent from the $\beta$ XDHNAD substrate to the flavin cofactor forming the $\operatorname{Ren}_{\text {red }} \bullet \beta-N A D^{+}$complex. The rate constants for flavin reduction $\left(k_{\text {red }}\right)$ are $234 \pm 7 \mathrm{~s}^{-1}$ and $860 \pm 190 \mathrm{~s}^{-1}$ for $\beta-6$ DHNAD and $\beta-2$ DHNAD 


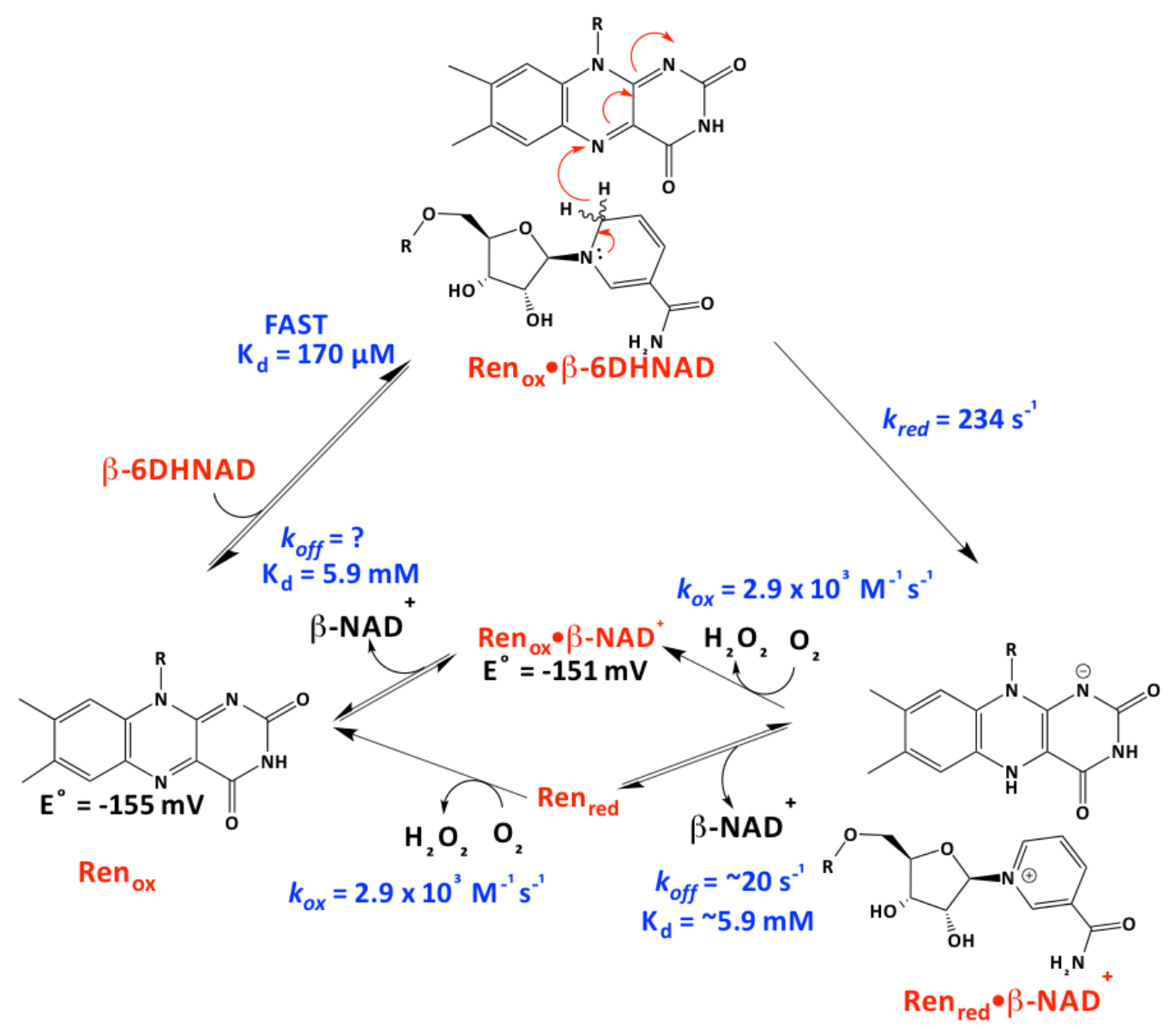

Scheme 4: The Catalytic Cycle of Renalase with 6DHNAD(P)

respectively. The reduced enzyme then either releases the $\beta-\mathrm{NAD}^{+}$(tentatively assigned as a 20 $\mathrm{s}^{-1}$ step) or reacts with dioxygen in a bimolecular reaction $\left(k_{o x}=3 \times 10^{3} \mathrm{M}^{-1} \mathrm{~s}^{-1}\right)$. The addition of exogenous $\beta-\mathrm{NAD}^{+}$has no influence on the rate constant for reoxidation, as such the oxidation of the flavin and the release of $\beta-\mathrm{NAD}^{+}$occur formally in random order. However under physiological conditions $\left(\sim 50-140 \mu \mathrm{M} \mathrm{O}_{2}\right)$ the observed rate constant for reoxidation of the flavin $\left(\sim 0.4 \mathrm{~s}^{-1}\right)$ dictates that $\beta-N A D^{+}$is the first product evolved and the reaction of the reduced enzyme with molecular oxygen will be largely rate limiting in turnover [69]. The reduction potentials of $\operatorname{Ren}_{\mathrm{ox}}$ and the $\operatorname{Ren}_{\mathrm{ox}} \bullet \beta-\mathrm{NAD}^{+}$complex were found to be $\sim-150 \mathrm{mV}$ indicating that 
the nicotinamide product does not significantly influence the behavior of the flavin, consistent with the equivalent $k_{o x}$ values determined for the $\operatorname{Ren}_{\mathrm{ox}}$ and $\operatorname{Ren}_{\mathrm{ox}} \bullet \beta-\mathrm{NAD}^{+}$states (Scheme 4).

One of the more curious aspects of the renalase substrate profile is that both 2 - and 6$\operatorname{DHNAD}(P)$ are substrates. This suggests that the amide substituent of the nicotinamide base can be accommodated in two positions within the active site such that the reductive complex remains positionally constant for both substrates (opposing ortho positions relative to the pyridyl nitrogen). If this were the case, both substrates would have non-catalytic binding modes in around $50 \%$ of associations. That this is not transmitted to the observed kinetics of the reductive half reaction data suggests that association and dissociation of both types of substrate in both orientations is rapid. Dual binding mode ligand association presumably also occurs with non-substrate nicotinamide dinucleotides such as $\beta-N A D(P)^{+}$and $\beta-N A D(P) H$ molecules. Titrations of these ligands indicate weaker associations than observed for the substrates by factors of only 3-4-fold for $\beta-N A D(P) H$ and $30-40$-fold for $\beta-N A D(P)^{+}$. The nonsubstrate ligands exist, however, in much higher concentrations in the cell, suggesting that renalase functions in a partially inhibitory ligand environment $[13,64,69]$.

\section{Integrative Conclusive Remarks}

In this review it is asserted that a true catalytic function for renalase has been identified. Renalase serves to oxidize $\beta$-NADH isomers in order to avoid the inhibitory effects of these molecules on primary metabolism. Its catalysis would appear to serve a housekeeping intracellular function rather than a extracellular systemic influence on pulmonary machinery. Given what is now known, it is reasonable to state both that renalase does not consume 
catecholamines and that it has no known catalytic function in blood plasma. Whether renalase has an influence on vascular tone and pulmonary function is not examined critically in this review. A moonlighting non-enzymatic function for renalase has the potential to explain some of the physiological claims for this protein and to this end the Desir group has recently reported that renalase acts as a cytokine independent of its catalytic activity [52]. 


\section{References}

[1] G.V. Desir, L. Wang, A.J. Peixoto, Human renalase: a review of its biology, function, and implications for hypertension, J Am Soc Hypertens, 6 (2012) 417-426.

[2] G.V. Desir, L. Tang, P. Wang, G. Li, B. Sampaio-Maia, J. Quelhas-Santos, M. Pestana, H. Velazquez, Renalase lowers ambulatory blood pressure by metabolizing circulating adrenaline, J Am Heart Assoc, 1 (2012) e002634.

[3] G. Desir, Novel insights into the physiology of renalase and its role in hypertension and heart disease, Pediatric nephrology, 27 (2012) 719-725.

[4] Y. Wu, J. Xu, H. Velazquez, P. Wang, G. Li, D. Liu, B. Sampaio-Maia, J. Quelhas-Santos, K. Russell, R. Russell, R.A. Flavell, M. Pestana, F. Giordano, G.V. Desir, Renalase deficiency aggravates ischemic myocardial damage, Kidney Int, 79 (2011) 853-860.

[5] G.V. Desir, Role of renalase in the regulation of blood pressure and the renal dopamine system, Curr Opin Nephrol Hypertens, 20 (2011) 31-36.

[6] F. Boomsma, K.F. Tipton, Renalase, a catecholamine-metabolising enzyme?, J Neural Transm, 114 (2007) 775-776.

[7] C. Fava, M. Montagnana, E. Danese, M. Sjogren, P. Almgren, G. Engstrom, B. Hedblad, G.C. Guidi, P. Minuz, O. Melander, The Renalase Asp37Glu polymorphism is not associated with hypertension and cardiovascular events in an urban-based prospective cohort: the Malmo Diet and cancer study, BMC Med Genet, 13 (2012) 57.

[8] J. Malyszko, J.S. Malyszko, D.P. Mikhailidis, J. Rysz, M. Zorawski, M. Banach, Hypertension and kidney disease: is renalase a new player or an innocent bystander?, J Hypertens, 30 (2012) 457-462. 
[9] S. Baroni, M. Milani, V. Pandini, G. Pavesi, D. Horner, A. Aliverti, Is renalase a novel player in catecholaminergic signaling? The mystery of the catalytic activity of an intriguing new flavoenzyme, Curr Pharma Design, 19 (2013) 2540-2551.

[10] J. Malyszko, H. Bachorzewska-Gajewska, S. Dobrzycki, Renalase, kidney and cardiovascular disease: Are they related or just coincidentally associated?, Adv Med Sci, 60 (2014) 41-49.

[11] J. Xu, G. Li, P. Wang, H. Velazquez, X. Yao, Y. Li, Y. Wu, A. Peixoto, S. Crowley, G.V. Desir, Renalase is a novel, soluble monoamine oxidase that regulates cardiac function and blood pressure, J Clin Inv, 115 (2005) 1275-1280.

[12] G.V. Desir, Renalase is a novel renal hormone that regulates cardiovascular function, J Am Soc Hypertens, 1 (2007) 99-103.

[13] M. Milani, F. Ciriello, S. Baroni, V. Pandini, G. Canevari, M. Bolognesi, A. Aliverti, FADbinding site and NADP reactivity in human renalase: a new enzyme involved in blood pressure regulation, J Mol Biol, 411 (2011) 463-473.

[14] B.A. Beaupre, B.R. Carmichael, M.R. Hoag, D.D. Shah, G.R. Moran, Renalase Is an alphaNAD(P)H Oxidase/Anomerase (JACS Spotlight Article), J Amer Chem Soc, 135 (2013) 1398013987.

[15] X. Li, R. Huang, Z. Xie, M. Lin, Z. Liang, Y. Yang, W. Jiang, Renalase, a new secretory enzyme: Its role in hypertensive-ischemic cardiovascular diseases, Med Sci Monit, 20 (2014) 688-692.

[16] R. Alhasan, D. Njus, The epinephrine assay for superoxide: why dopamine does not work, Anal Biochem, 381 (2008) 142-147.

[17] H.P. Misra, I. Fridovich, The role of superoxide anion in the autoxidation of epinephrine and a simple assay for superoxide dismutase, J Biol Chem, 247 (1972) 3170-3175. 
[18] S. Ito, Reexamination of the structure of eumelanin, Biochim Biophys Acta, 883 (1986) 155161.

[19] V. Massey, Activation of molecular oxygen by flavins and flavoproteins, J Biol Chem, 269 (1994) 22459-22462.

[20] B. Fornstedt, Role of catechol autooxidation in the degeneration of dopamine neurons, Acta Neurol Scand. Supplem, 129 (1990) 12-14.

[21] B. Kalyanaraman, P.I. Premovic, R.C. Sealy, Semiquinone Anion Radicals from Addition of Amino-Acids, Peptides, and Proteins to Quinones Derived from Oxidation of Catechols and Catecholamines - an Electron-Spin-Resonance Spin Stabilization Study, J Biol Chem, 262 (1987) 11080-11087.

[22] N. Eikelis, S.C. Hennebry, G.W. Lambert, M.P. Schlaich, Does renalase degrade catecholamines?, Kidney Int, 79 (2011) 1380-1381.

[23] V. Pandini, F. Ciriello, G. Tedeschi, G. Rossoni, G. Zanetti, A. Aliverti, Synthesis of human renalase1 in Escherichia coli and its purification as a FAD-containing holoprotein, Prot Expr Purif, 72 (2010) 244-253.

[24] J. Xu, G.V. Desir, Renalase, a new renal hormone: its role in health and disease, Curr Opin Nephrol Hypertens, 16 (2007) 373-378.

[25] Q. Zhao, Z. Fan, J. He, S. Chen, H. Li, P. Zhang, L. Wang, D. Hu, J. Huang, B. Qiang, D. Gu, Renalase gene is a novel susceptibility gene for essential hypertension: a two-stage association study in northern Han Chinese population, J Mol Med (Berl), 85 (2007) 877-885.

[26] G.V. Desir, Renalase deficiency in chronic kidney disease, and its contribution to hypertension and cardiovascular disease, Curr Opin Nephrol Hypertens, 17 (2008) 181-185. 
[27] G. Li, J. Xu, P. Wang, H. Velazquez, Y. Li, Y. Wu, G.V. Desir, Catecholamines regulate the activity, secretion, and synthesis of renalase, Circulation, 117 (2008) 1277-1282.

[28] G.V. Desir, Regulation of blood pressure and cardiovascular function by renalase, Kidney Int, 76 (2009) 366-370.

[29] R. Farzaneh-Far, G.V. Desir, B. Na, N.B. Schiller, M.A. Whooley, A functional polymorphism in renalase (Glu37Asp) is associated with cardiac hypertrophy, dysfunction, and ischemia: data from the heart and soul study, PLoS One, 5 (2010) e13496.

[30] A.E. Medvedev, A.V. Veselovsky, V.I. Fedchenko, Renalase, a new secretory enzyme responsible for selective degradation of catecholamines: achievements and unsolved problems, Biochemistry. Biokhimiia, 75 (2010) 951-958.

[31] M. Buraczynska, P. Zukowski, K. Buraczynska, S. Mozul, A. Ksiazek, Renalase gene polymorphisms in patients with type 2 diabetes, hypertension and stroke, Neuromolecular Med, 13 (2011) 321-327.

[32] R. Gu, W. Lu, J. Xie, J. Bai, B. Xu, Renalase deficiency in heart failure model of rats--a potential mechanism underlying circulating norepinephrine accumulation, PLoS One, 6 (2011) e14633.

[33] P. Przybylowski, J. Malyszko, S. Kozlowska, E. Koc-Zorawska, M. Mysliwiec, Serum renalase depends on kidney function but not on blood pressure in heart transplant recipients, Transplant Proc, 43 (2011) 3888-3891.

[34] A. Baraka, S. El Ghotny, Cardioprotective effect of renalase in 5/6 nephrectomized rats, J Cardiovasc Pharmacol Ther, 17 (2012) 412-416. 
[35] Y. Guo, W. Jiang, [Research progress with renalase and cardiovascular disease], Zhong Nan Da Xue Xue Bao Yi Xue Ban, 37 (2012) 537-540.

[36] E. Zbroch, J. Malyszko, E. Koc-Zorawska, M. Mysliwiec, Renalase, kidney function, and markers of endothelial dysfunction in renal transplant recipients, Pol Arch Med Wewn, 122 (2012) 40-44.

[37] E. Zbroch, J. Malyszko, J.S. Malyszko, E. Koc-Zorawska, M. Mysliwiec, Renalase, a novel enzyme involved in blood pressure regulation, is related to kidney function but not to blood pressure in hemodialysis patients, Kidney Blood Press Res, 35 (2012) 395-399.

[38] B. Czarkowska-Paczek, M. Zendzian-Piotrowska, K. Gala, M. Sobol, L. Paczek, Exercise differentially regulates renalase expression in skeletal muscle and kidney, Tohoku J Exp Med, 231 (2013) 321-329.

[39] H.T. Lee, J.Y. Kim, M. Kim, P. Wang, L. Tang, S. Baroni, V.D. D'Agati, G.V. Desir, Renalase protects against ischemic AKI, J Am Soc Nephrol, 24 (2013) 445-455.

[40] P. Przybylowski, E. Koc-Zorawska, J.S. Malyszko, M. Mysliwiec, J. Malyszko, Renalase and endothelial dysfunction in heart transplant recipients, Transplant Proc, 45 (2013) 394-396.

[41] D. Sizova, H. Velazquez, B. Sampaio-Maia, J. Quelhas-Santos, M. Pestana, G.V. Desir, Renalase regulates renal dopamine and phosphate metabolism, Am J Physiol Renal Physiol, 305 (2013) F839-844.

[42] E. Zbroch, E. Koc-Zorawska, J. Malyszko, M. Mysliwiec, Circulating levels of renalase, norepinephrine, and dopamine in dialysis patients, Renal Failure, 35 (2013) 673-679.

[43] G.V. Desir, A.J. Peixoto, Renalase in hypertension and kidney disease, Nephrol Dial Transplant, 29 (2014) 22-28. 
[44] P.J. Sonawane, V. Gupta, B.K. Sasi, A. Kalyani, B. Natarajan, A.A. Khan, B.S. Sahu, N.R. Mahapatra, Transcriptional Regulation of the Novel Monoamine Oxidase Renalase: Crucial Roles of Transcription Factors Sp1, STAT3, and ZBP89, Biochemistry, 53 (2014) 6878-6892.

[45] F. Wang, H. Cai, Q. Zhao, T. Xing, J. Li, N. Wang, Epinephrine Evokes Renalase Secretion via alpha-Adrenoceptor/NF-kappaB Pathways in Renal Proximal Tubular Epithelial Cells, Kidney Blood Press Res, 39 (2014) 252-259.

[46] F. Wang, B. Huang, J. Li, L. Liu, N. Wang, Renalase might be associated with hypertension and insulin resistance in Type 2 diabetes, Renal Failure, 36 (2014) 552-556.

[47] F. Wang, J. Li, T. Xing, Y. Xie, N. Wang, Serum renalase is related to catecholamine levels and renal function, Clin Exp Nephrol, (2014).

[48] Y. Wang, F.Q. Liu, D. Wang, J.J. Mu, K.Y. Ren, T.S. Guo, C. Chu, L. Wang, L.K. Geng, Z.Y. Yuan, Effect of salt intake and potassium supplementation on serum renalase levels in Chinese adults: a randomized trial, Medicine (Baltimore), 93 (2014) e44.

[49] M.T. Wybraniec, K. Mizia-Stec, O. Trojnarska, J. Chudek, B. Czerwienska, M. Wikarek, A. Wiecek, Low plasma renalase concentration in hypertensive patients after surgical repair of coarctation of aorta, J Am Soc Hypertens, 8 (2014) 464-474.

[50] J. Quelhas-Santos, M. Pestana, Plasma Renalase Expression in Chronic Kidney Disease: Differences and Similarities between Humans and Rats, Curr Hypertens Rev, (2015).

[51] S.C. Hennebry, N. Eikelis, F. Socratous, G. Desir, G. Lambert, M. Schlaich, Renalase, a novel soluble FAD-dependent protein, is synthesized in the brain and peripheral nerves, Mol Psychiatry, 15 (2010) 234-236. 
[52] X. Guo, L. Wang, H. Velazquez, R. Safirstein, G.V. Desir, Renalase: its role as a cytokine, and an update on its association with type 1 diabetes and ischemic stroke, Curr Opin Nephrol Hypertens, 23 (2014) 513-518.

[53] F. Wang, Q. Zhao, T. Xing, J. Li, N. Wang, Renalase-specific polyclonal antibody and its application in the detection of renalase's expression, Hybridoma (Larchmt), 31 (2012) 378-381.

[54] M. Zhou, T. Liang, Y. Wang, D. Jin, J. Wang, L. Jia, S. Zhang, Expression and tissue localization of renalase, a novel soluble FAD-dependent protein, in reproductive/steroidogenic systems, Mol Biol Rep, 40 (2013) 3987-3994.

[55] M. Wilhelm, J. Schlegl, H. Hahne, A. Moghaddas Gholami, M. Lieberenz, M.M. Savitski, E. Ziegler, L. Butzmann, S. Gessulat, H. Marx, T. Mathieson, S. Lemeer, K. Schnatbaum, U. Reimer, H. Wenschuh, M. Mollenhauer, J. Slotta-Huspenina, J.H. Boese, M. Bantscheff, A. Gerstmair, F. Faerber, B. Kuster, Mass-spectrometry-based draft of the human proteome, Nature, 509 (2014) 582-587.

[56] V.I. Fedchenko, A.A. Kaloshin, L.M. Mezhevikina, O.A. Buneeva, A.E. Medvedev, Construction of the coding sequence of the transcription variant 2 of the human renalase gene and its expression in the prokaryotic system, Int J Mol Sci, 14 (2013) 12764-12779.

[57] H.A. Schreuder, P.A. Prick, R.K. Wierenga, G. Vriend, K.S. Wilson, W.G. Hol, J. Drenth, Crystal structure of the p-hydroxybenzoate hydroxylase-substrate complex refined at $1.9 \mathrm{~A}$ resolution. Analysis of the enzyme-substrate and enzyme-product complexes, J Mol Biol, 208 (1989) 679-696.

[58] N.B. Birchfield, B. Latli, J.E. Casida, Human protoporphyrinogen oxidase: Relation between the herbicide binding site and the flavin cofactor, Biochemistry, 37 (1998) 6905-6910. 
[59] H. Mizutani, I. Miyahara, K. Hirotsu, Y. Nishina, K. Shiga, C. Setoyama, R. Miura, Threedimensional structure of porcine kidney D-amino acid oxidase at $3.0 \AA$ resolution, J Biochem, 120 (1996) 14-17.

[60] A. Faust, K. Niefind, W. Hummel, D. Schomburg, The structure of a bacterial L-amino acid oxidase from Rhodococcus opacus gives new evidence for the hydride mechanism for dehydrogenation, J Mol Biol, 367 (2007) 234-248.

[61] P.D. Pawelek, J. Cheah, R. Coulombe, P. Macheroux, S. Ghisla, A. Vrielink, The structure of L-amino acid oxidase reveals the substrate trajectory into an enantiomerically conserved active site, EMBO, 19 (2000) 4204-4215.

[62] Y. Chen, Y. Yang, F. Wang, K. Wan, K. Yamane, Y. Zhang, M. Lei, Crystal structure of human histone lysine-specific demethylase 1 (LSD1), P Natl Acad Sci USA, 103 (2006) 13956-13961.

[63] K. Crozier-Reabe, G.R. Moran, Form follows function: structural and catalytic variation in the class a flavoprotein monooxygenases, Int J Mol Sci, 13 (2012) 15601-15639.

[64] B.A. Beaupre, M.R. Hoag, B.R. Carmichael, G.R. Moran, Kinetics and equilibria of the reductive and oxidative half-reactions of human renalase with alpha-NADPH, Biochemistry, 52 (2013) 8929-8937.

[65] R.R. Gosh, T.W.B. Gehr, D.A. Sica, S. Masilamani, I. Fakhry, R. Wang, E. Mcquire, S. Gosh, Effect of renalase inhibition on blood pressure. , J Am Soc Nephrol, 17 (2006) 208A (abstract).

[66] P. He, G.R. Moran, Structural and mechanistic comparisons of the metal-binding members of the vicinal oxygen chelate (VOC) superfamily, J Inorg Biochem, 105 (2011) 1259-1272.

[67] J. Wang, S. Qi, W. Cheng, L. Li, F. Wang, Y.Z. Li, S.P. Zhang, Identification, expression and tissue distribution of a renalase homologue from mouse, Mol Biol Rep, 35 (2008) 613-620. 
[68] D.T. Sawyer, J.S. Valentine, How Super is Superoxide ?, Acc. Chem. Res., 14 (1981) 393-400.

[69] B.A. Beaupre, M.R. Hoag, J. Roman, F.H. Forsterling, G.R. Moran, Metabolic Function for Human Renalase: Oxidation of Isomeric Forms of beta- $\mathrm{NAD}(\mathrm{P}) \mathrm{H}$ that Are Inhibitory to Primary Metabolism, Biochemistry, 54 (2015) 795-806.

[70] A. Klemm, T. Steiner, U. Flotgen, G.A. Cumme, A. Horn, Determination, purification, and characterization of alpha-NADH and alpha-NADPH, Meth Enzymol, 280 (1997) 171-186.

[71] N.J. Oppenheimer, Chemistry and Solution Confromation of Pyridine Nucleotides, in: J. Everse, B. Anderson, K.-S. You (Eds.) The Pyridine Nucletide coenzymes, Academic Press Inc., Place Published, 1982, pp. 51-90.

[72] N.J. Oppenheimer, N.O. Kaplan, The alpha beta epimerization of reduced nicotinamide adenine dinucleotide, Arch Biochem Biophys, 166 (1975) 526-535.

[73] M.B. Mathews, E.E. Conn, The Reaction of Diphosphopyridine Nucleotide with Sodium Borohydride, J Amer Chem Soc, 75 (1953) 5428-5430.

[74] K. Chakraverty, L. King, J.G. Watson, S. Chaykin, Reduced 1,6-dihydrodiphosphopyridine nucleotide. Chemical properties and enzymatic modification, J Biol Chem, 244 (1969) 42084217.

[75] S. Chaykin, L. King, J.G. Watson, The reduction of DPN+ and TPN+ with sodium borohydride, Biochim Biophys Acta, 124 (1966) 13-25.

[76] S. Chaykin, K. Chakraverty, L. King, J.G. Watson, Tritium-labeled DPN+ and TPN+, Biochim Biophys Acta, 124 (1966) 1-12.

[77] S. Chaykin, L. Meissner, The borohydride reduction products of DPN, Biochem Biophys Res Comm, 14 (1964) 233-240. 
[78] K. Chakraverty, S. Chaykin, 1,6 DPNH, an enzymatically active form of reduced DPN, Biochem Biophys Res Comm, 15 (1964) 262-268.

[79] O.H. Lowry, J.V. Passonneau, M.K. Rock, The stability of pyridine nucleotides, J Biol Chem, 236 (1961) 2756-2759.

[80] K. Dalziel, The purification of nicotinamide adenine dinucleotide and kinetic effects of nucleotide impurities, J Biol Chem, 238 (1963) 1538-1543.

[81] S.E. Godtfredsen, M. Ottesen, 1,6-Dihydro-NAD as an Humidity-Induced Lactate Dehydrogenase Inhibitor in NADH Preparations, Carlesberg Res Comm, 43 (1978) 171-175. 


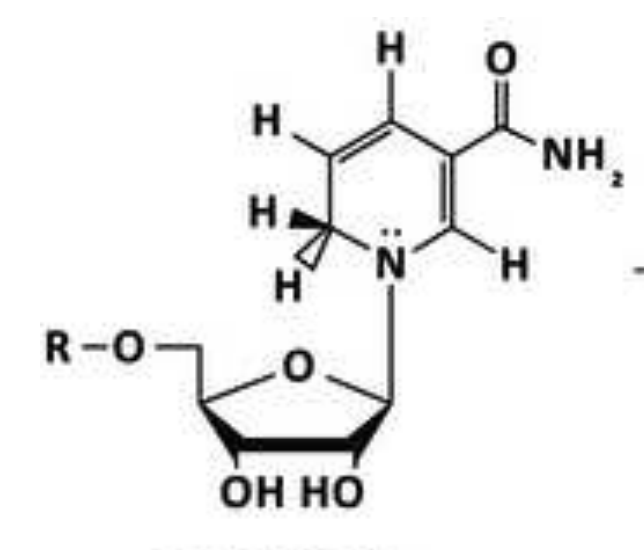

6DHNAD(P)

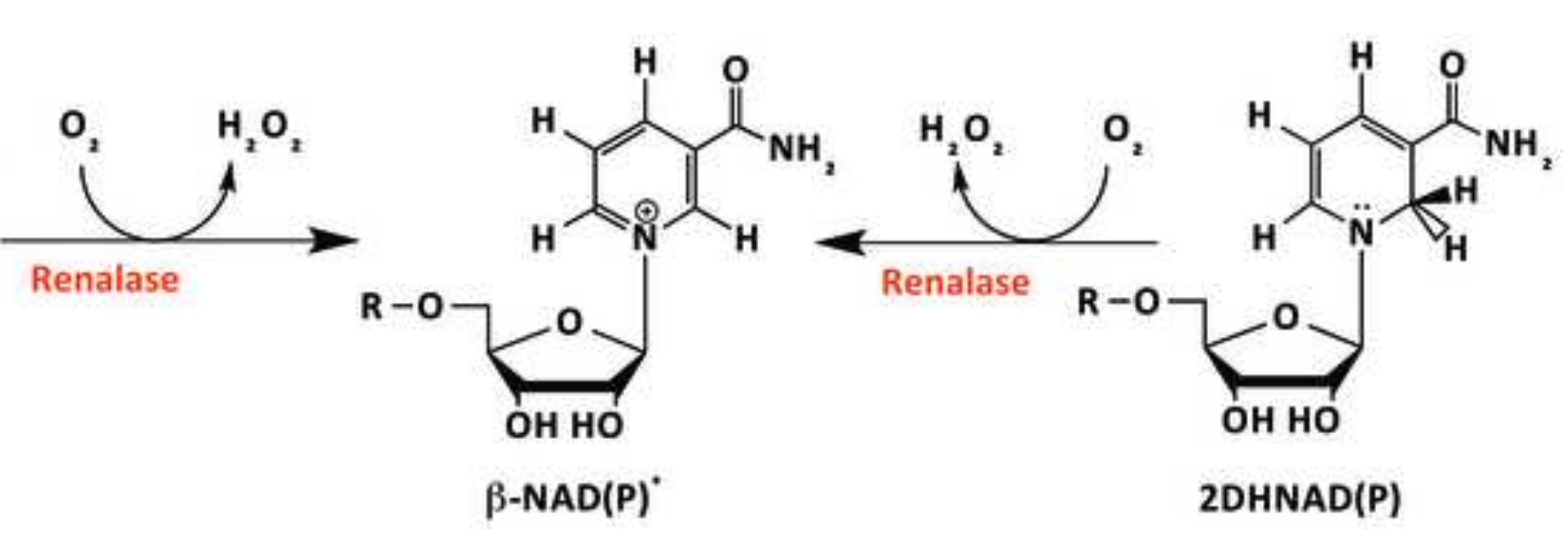

$\beta$-NAD(P) ${ }^{*}$
2DHNAD(P)

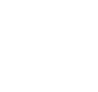

DHNAD(P) 